\title{
Legados da professora Ruth Cardoso ao Governo Federal
}

E lisabete Ferrarezi

No dia 24 de junho de 2008, a nação se comoveu com a morte repentina de D ona Ruth Cardoso. Homenagens partiram de todos os lados, destacando a multiplicidade de contribuições dessa mulher discreta e atuante, bem como 0 reconhecimento alcançado em todos os setores dos quais participou.

Este texto presta especial homenagem à cientista, ativista social e servidora pública Ruth Cardoso, que criou e presidiu o Conselho da Comunidade Solidária no G overno Federal, no período 1995-2002, momento em que se arriscou a propor o novo, enfrentou a polêmica e introduziu questionamentos em torno das antigas formas de relação do Estado com a sociedade. Reconhecer seu papel é valorizar as pessoas que acreditam ser possível fazer a diferença na administração pública brasileira.

Tive o privilégio de testemunhar essa trajetória. Como assessora, pude perceber a dedicação de D ona Ruth para colocar em prática seus sonhos e projetos. Minha admiração passa pelo modo como ela enfrentava as resistências, 
pela ousadia em inovar e trazer questões polêmicas para o debate público, pela autonomia que exercia e que nos conferia nos projetos. Pela confiança que depositou numa equipe, em sua maioria, cedida por outros órgãos do governo. Passa também por ter conhecido sua solidariedade inata, sincera, revelada pela preocupação com 0 bem-estar das pessoas com as quais trabalhava direta ou indiretamente.

Tive a oportunidade de dialogar com ela, especialmente durante a elaboração de minha tese de doutorado sobre a reforma do marco legal do terceiro setor, quando a entrevistei. Trago aqui alguns trechos do seu depoimento sobre a concepção e a experiência do Conselho eresumo as ações da Comunidade Solidária, esperando com isso contribuir para que o legado possa vir a ser pesquisado e se torne conhecimento e memória.

O Conselho da Comunidade Solidária (chamado de braço da sociedade civil) pretendia constituir-se em "um novo instrumento de diálogo político e de promoção de parcerias entre Estado e sociedade para o enfrentamento da pobreza e da exclusão por intermédio de iniciativas inovadoras de desenvolvimento social" (Conselho da Comunidade SolidÁRIA, 1999: 4).

A expectativa de que 0 Conselho, por ser dirigido pela primeira-dama, assumiria a área social, não se cumpriu. Na realidade, o projeto tinha uma visão crítica do padrão histórico da política social brasileira. Segundo Ruth Cardoso, não havia sentido em criar outra instituição como a Legião Brasileira de Assistência (1942-2005), que foi extinta no início do governo, nem tampouco criar um fundo para o combate à pobreza para competir com as políticas dos ministérios - 0 que faria com que as pessoas se organizassem em função das diretrizes desse Fundo do governo para obter os recursos. Ela não queria criar uma instituição que perdurasse, mas que programas fossem criados por meio de parcerias, aproveitando os recursos existentes na sociedade, além de trazer "questões" que o Estado não estava enxergando. Foi assim que criou 0 Conselho, que, tal como os programas, deveria acabar quando atingisse suas metas ${ }^{1}$ (CARD o so, entrevista à autora, 6/ 11/ 06).

0 pano de fundo dessa proposta originou-se na experiência pregressa da professora Ruth Cardoso, que foi militante do movimento feminista, apoiou a ação de outros movimentos - como o dos negros e o dos direitos humanos - e entrou em contato com novas formas de organização e mobilização social, nos anos 70, quando realizou pesquisas em bairros de São Paulo. Também de sua experiência orientando alunos: "Eu tinha esse conhecimento sobre a organização de base da sociedade, tinha muita gente discutindo isso comigo e explorei 0 assunto nos anos 80". Ela considerou que toda essa experiência foi importante porque se diferenciava da visão corrente na esquerda, nas décadas de 70 e 80, visão segundo a qual a mudança social ocorreria por meio da ação partidária. Suas pesquisas indicavam que a sociedade era mais informada e mobilizada do que se imaginava à época, o que seria percebido depois, por exemplo, na mobilização de atores sociais na Constituinte em 1988 (CARDOSO, entrevista à autora, 6/ 11/ 06).

"Tinha uma mobilização [eleições para os governos locais na década de 80 , movimentos populares], coisas que surgiam da própria realidade, e os intelectuais mais atentos perceberam 
esse fenômeno, as organizações de base da sociedade" (CARD O So, entrevista à autora, 6/11/ 06).

Q uando D ona Ruth estava fazendo um pós-doutorado nos Estados Unidos, estudando um novo tema - a juventude -, seu marido, o sociólogo Fernando Henrique Cardoso, ganhou as eleições à Presidência da República. Ela então começou a pensar no que iria fazer. Tinha algumas convicções e havia feito constatações, mas como colocaria isso em prática? Sua experiência e conhecimento de pesquisadora do Centro Brasileiro de Análise e Planejamento - Cebrap, e de docência na Universidade de São Paulo USP, ajudariam-na a desenhar o projeto e renderiam algumas práticas diferenciadas no setor público.

"Levei comigo a certeza de que a sociedade brasileira tinha uma teia de comunicação no nível local, as grass roots, e isso era o resultado do que eu tinha visto, pesquisado, conversado. Acho que foi isso que me levou à idéia do Comunidade Solidária. 0 tema era a parceria Estado-sociedade. Mas 0 Estado era alheio aos novos atores. As políticas públicas tinham que encontrar um novo caminho de diálogo com a sociedade, e a parceria ficou a briga maior" (CARDOSO, entrevista à autora, 6/11/ 06).

A agenda do Conselho da Comunidade Solidária traduzia propostas de setores progressistas que atuaram na Constituinte, que pretendiam, diferentemente da proposta neoliberal de reduzir 0 papel do Estado, incluir formas complementares de provisão, por meio do terceiro setor, e reformar e fortalecer a

ação do Estado. Era imprescindível lidar com os desafios advindos das mudanças do capitalismo, da globalização e democratização e resolver os aspectos críticos do sistema de políticas sociais, como a centralização, fragmentação, burocratização e apropriação do aparelho estatal por interesses privados e corporativos, 0 distanciamento das necessidades da comunidade, a má qualidade e exclusão de segmentos de mais baixa renda por

\section{"Parceria não é} entrar em programas de governo. Parcenia é ter diagnóstico de setores que não estão cobertos e não podem sersuficientemente ofertados por parte do governo."

\section{Ruth Cardoso}

parte do Estado.Já nos anos 90, sob ajuste fiscal e escassez de recursos, figuravam na agenda a descentralização, a necessidade de estabelecer prioridades de ação, a busca de novas formas de articulação com a sociedade civil e com o mercado, a participação e a introdução de novas formas de gestão nas organizações estatais.

Havia, assim, uma tentativa de configurar políticas públicas em que o Estado 
não fosse 0 único a gerar solidariedade e ofertar serviços, mas que assumisse a articulação de políticas públicas protagonizadas pelos novos atores.

D ona Ruth acreditava na realização de parcerias, com metas e controle de resultados, usando recursos existentes na sociedade. Citou a atuação das ONG s que, no processo de democratização, assumiram tarefas, prestaram serviços muito particulares, e não suficiente e eficientemente ofertados pelo Estado, tais como o trabalho com crianças em situação de rua, atendimento a portadores de deficiências e a idosos. À sociedade civil caberia complementar a ação do Estado em atividades específicas, nas quais era diagnosticada como mais eficiente e eficaz. "Parceria não é entrar em programas de governo. Parceria é ter diagnóstico de setores que não estão cobertos e não podem ser suficientemente ofertados por parte do governo" (CARD O so, entrevista à autora, 6/11/ 06).

Segundo Ruth Cardoso, o Estado deve cumprir seu papel universalista, definir prioridades das políticas públicas, e para dispor de recursos públicos tem que obedecer às regras e submeter-se a controles no uso do dinheiro público nas parcerias.

Q uando perguntada sobre uma das críticas que recebia, que estaria terceirizando os serviços sociais do Estado, ela respondeu: "Não é terceirização porque é a sociedade que está criando. (...) Percebemos a nova posição da sociedade civil que passou a não só advogar, mas prestar serviços inovadores e por isso parceria, porque a sociedade é capaz de inovar".

A dirigente do Conselho, à época, também percebeu que havia um novo discurso dos empresários (responsabilidade social) e estava aberta à participação deles. 0 novo papel consistia em articular parceiros e coordenar ações. "Não fomos nós que mudamos as cabeças, foi a sociedade que mudou. (...) Eram novos atores [que estavam] disponíveis, e o governo não reconhecia nenhum desses atores".

Foi assim que deu início ao Conselho, levando algumas constatações que foram traduzindo-se em práticas e programas, apontando formas alternativas de provisão de serviços públicos.

O Conselho dispunha de uma Secretaria Executiva, responsável pelo Programa Comunidade Solidária que articulava e focalizava as ações governamentais em municípios selecionados, coordenava a rede de gestores dos ministérios setoriais, dos Estados e municípios, que conduziam programas prioritários de combate à fome e à pobreza. Os programas eram executados pelos ministérios em municípios mais carentes de cada E stado, e eram selecionados em função de sua capacidade de melhorar as condições de vida das populações mais pobres. Apesar de formalmente existir essa SecretariaExecutiva (chamada de braço governamental), ela de fato nunca exerceu o papel de Secretaria-Executiva do Conselho, atuando basicamente na gestão do Programa Comunidade Solidária.

À medida que o ideário do Conselho acumulava conhecimento e tornava-se mais fortalecido, resolveu mudar seu braço governamental, articulando oferta de programas públicos com a demanda, por meio da mobilização do capital social, de modo que os beneficiários e atores políticos locais pudessem opinar e tomar decisões sobre seus destinos, participando da formulação e implementação das ações propostas em um plano de desenvolvimento.

Deste modo, a partir de 1999, o Programa Comunidade Solidária da 
Secretaria-Executiva foi substituído pelo Programa Comunidade A tiva, que promovia uma estratégia de D esenvolvimento Local Integrado e Sustentável, de base participativa. À Secretaria Executiva caberia então auxiliar os Fóruns de D esenvolvimento locais na negociação com órgãos do G overno Federal, estadual e municipal para viabilizar seus planos de desenvolvimento.

A opção pela constituição de um Conselho implicou limitações na estrutura, em relação a recursos financeiros e humanos. Mas D ona Ruth tinha preferência pelos programas que tivessem parcerias. "D emonstramos que essa idéia não era sonho, era possível", referindo-se aos programas gerenciados por associações civis que criou e que existem até hoje. "Fazíamos ação coordenada entre parceiros com diagnóstico, planejamento, metas, objetivos. (...) Era uma lição que queríamos dar [os programas], agora está difícil [fazer parcerias] porque as empresas têm suas próprias ações."

Como empreendedora que era, D ona Ruth conseguiu unir ONGs, empresários e Governo Federal colocando em prática novos arranjos institucionais que envolviam articulação de parceiros públicos e privados com diferentes tipos de recursos para viabilizar programas.

0 primeiro foi criado em 1995, com a Associação de Apoio ao Programa Capacitação Solidária, que articulava parcerias e captava recursos de empresas para a realização de capacitação profissional de jovens. Isso era feito por meio de seleção de projetos de $0 \mathrm{NGs}$, com monitoramento e avaliação de resultados. Os objetivos eram treinar os jovens em uma habilidade específica; promover a sociabilidade, comunicação, auto-estima e cidadania; incentivar o interesse em ampliar seus conhecimentos e retomar ou reforçar a relação com a escola; e estimular soluções criativas e inovadoras de geração de renda e de identificação de novos nichos no mercado de trabalho.

O Programa Universidade Solidária (1996) atuava mobilizando jovens universitários, permitindo-lhes conhecer a realidade do País e participar de um exercício de responsabilidade social, em visitas a municípios com altos índices de pobreza. O Programa Alfabetização Solidária (1997) identificava os municípios, mobilizava e articulava parcerias para executálo. Seu objetivo era reduzir o índice de analfabetismo entre jovens e adultos e desencadear a oferta pública de educação a esse segmento.

O Programa Voluntários (1997) promovia o voluntariado no País, a participação responsável e solidária dos cidadãos em iniciativas de combate à exclusão social e busca da melhoria da qualidade de vida em comum. 0 Artesanato Solidário (1998) auxiliava as comunidades artesanais a viabilizar planos de trabalho para apoiar o que já fazem e ampliar o número de pessoas envolvidas. O Projeto Rede Jovem promovia o acesso à internet a jovens.

Em 1997, o Conselho deu origem ao Programa Voluntários, à Rede de Informações para o terceiro setor na internet RITS eàreforma do marco legal do terceiro setor para viabilizar a proposta de fortalecimento da sociedade civil. Também abriu um processo de construção de consensos em torno dos temas considerados fundamentais de uma agenda social, com as chamadas rodadas de interlocução política, que envolvia a participação de atores governamentais e não-governamentais na discussão e implementação das propostas acordadas². 
A concepção favorável à promoção de relações de cooperação entre o Estado e a OSC constituiu uma mudança considerável se comparada à relação antagônica predominante desde a ditadura militar, e ao padrão clientelista e assistencialista prevalecente nas políticas sociais. 0 pressuposto da disseminação de novos arranjosinstitucionais era que a reconstrução do Estado passava pelo fortalecimento e pela publicização de suas ações e, por isso, envolvia também a redefinição de suas relações com a sociedade civil.

A presidente do Conselho desempenhou papel fundamental na fase em que o tema terceiro setor passou a compor a agenda de governo, por meio dos programas e discursos, e quando a reforma do marco legal do terceiro setor conseguiu chegar à agenda decisória, congregando ministros importantes no processo. Segundo ela, nas conversas com as O NG s, elas falavam da dificuldade de criar parcerias, da burocracia. $\mathrm{O}$ marco legal era muito fragmentado, disperso, desestruturado. Falar em parceria com esse marco legal não era possível. "ONG não é nada em termos jurídicos, havia a necessidade de uma categoria específica" (CARDoso, entrevista à autora, 6/11/ 06).

D eu-se início, em 1997, a um espaço dialógico entre governo e OSC, para discussão da reforma do marco legal do terceiro setor. "Conseguimos colocar atores muito diferenciados que não estavam acostumados a entrar em diálogo desse tipo. Nós ampliamos o debate com áreas novas do terceiro setor, que não tinham voz" (CARD o so, entrevista à autora, $6 / 11 / 06)$.

0 principal produto da reforma foi a Lei 9.790/ 99 que criou a qualificação (título) de Oscip (O rganização da Sociedade Civil de Interesse Público). Seu arcabouço conceitual foi influenciado por alguns dos princípios da reforma gerencial proposta pelo Governo Federal, pelas mudanças nos papéis do Estado e da sociedade e pelo projeto político da Comunidade Solidária. Além disso, contou com apoio da comunidade de política das ONG s que estava debatendo a inadequação da legislação, considerada antiga e desatualizada (de 1935 e 1950), e era restrita a algumas áreas e a alguns tipos de organização tradicionais. A nova lei pretendia institucionalizar uma prática antiga, mas insuficientemente regulamentada, até então, que era a atuação pública de atores privados sem fins lucrativos.

0 formato institucional do título pretendia incentivar a gestão mais transparente e eficiente, e incentivar a participação das OSC por meio do termo de parceria, que buscava flexibilizar o controle dos meios tendo como contrapartida transparência, mecanismos de avaliação de resultados, de controle público e social mais rigorosos, com sanções no caso de uso indevido de recursos.

Os empreendedores D ona Ruth e o Conselheiro Augusto de Franco, mentor da interlocução política e coordenador da reforma da legislação, esforçaram-se para convencer as autoridades sobre suas concepções acerca do problema: 0 não reconhecimento institucional e legal das ONGs de novo tipo, com fins públicos, que surgiram durante a democratização, e a importância de seu fortalecimento, enquanto meio para gerar capital social nas comunidades, sem o qual não haveria desenvolvimento social.

A Lei $\mathrm{n}^{0}$ 9.790/99 foi produto da discussão democrática e persuasão recíproca de atores políticos governamentais, não governamentais, participantes em graus diferenciados de suas decisões. A formação 
do consenso na sua elaboração ocorreu mediante processamento de conflitos e negociação de interesses contraditórios, gerando um espaço público em que tanto os opositores quanto os defensores da lei estiveram dispostos a realizar negociações e sacrifícios, que ocorreram tanto no poder executivo, quanto no legislativo.

Esse pequeno resumo da experiência da Comunidade Solidária permite-nos identificar D ona Ruth Cardoso como uma empreendedora de destaque desse processo, pelo menos em dois sentidos. Um deles, com base em Kingdon, (1995), em que se destaca seu papel na transformação de algumas idéias em programas inovadores, aproveitando a janela de oportunidade política que se abriu com a Presidência do Conselho e com o ambiente favorável a mudanças, principalmente à reestruturação do papel do Estado e à revitalização do papel das organizações da sociedade civil na esfera pública.

0 segundo sentido diz respeito ao comportamento empreendedor, à autonomia, inovação, autenticidade, assunção de riscos, criatividade e aos valores que a motivaram, aos seus objetivos políticos democráticos, cooperação, solidariedade, ética pública. Seu trabalho não foi criar uma grande instituição, nem desenhar grandes projetos, mas foi o de vagarosamente demonstrar que programas em parceria eram possíveis de serem feitos, e aumentavam o valor público das ações. E com essa influência na agenda pública, Ruth Cardoso gerou projetos e mudanças que foram sendo disseminadas lentamente.

Talvez ela não concordasse com essa opinião, e talvez ela própria não tivesse a dimensão de seu papel e de suas contribuições para a geração de novos arranjos institucionais nas políticas públicas no Governo Federal. Cabe agora aos pesquisadores investigar o legado deixado, as propostas, os programas, os resultados e impactos para que as contribuições e as críticas sobre o modelo possam ser debatidas na esfera pública, tal como o fez Dona Ruth.

(Artigo recebido em junho de 2008. Versão final em julho de 2008).

\section{Notas}

${ }^{1}$ A pós sair do governo, D ona Ruth criou a O NG Comunitas, que herdou alguns dos programas criados pelo Conselho da Comunidade Solidária.

${ }^{2}$ As principais rodadas de interlocução foram: Reforma Agrária, Renda Mínima e Educação Fundamental, Segurança Alimentar e Nutricional, Criança e A dolescente, Alternativas de O cupação e Renda, D esenvolvimento Local Integrado e Sustentável, Marco Legal do Terceiro Setor e aExpansão do Microcrédito no Brasil.

\section{Referências bibliográficas}

Brasil. Conselho Comunidade Solidária. O Conselho da Comunidade Solidária. Texto para novos conselheiros. Brasília: março 1999 (mimeo). 
CARD OSO, Ruth. Entrevistaà autora(Elisabete Ferrarezi), São Paulo, 6/ 11/ 2006. 2 fitas cassetes. Cardoso, Ruth. De Franco, Augusto. Darcy, Miguel. Um novo referencial para a ação do E stado e da Sociedade - Sete ligóes da ex periência da Comunidade Solidária, Brasília: PNUD/ Comunidade Solidária, 2000.

FerRarezi, Elisabete. A Reforma do Marco Legal do Terceiro Setor: A criação da Lei das O SCIP (Lei 9.790/99). Tese de doutorado apresentada ao Departamento de Sociologia da Universidade de Brasília, Brasília, 2007.

KingD ON, John W. A gendas, alternatives and public policies. 2a ed. EUA: Longman, 1995.

Elisabete Ferrarezi

D outora em Sociologia pela Universidade de Brasília, mestre em Administração Pública pela FGV/ SP. É atualmente Coordenadora Geral de Pesquisa da ENAP. Pertence à carreira do Governo Federal de Especialista em Políticas Públicas e G estão Governamental desde 1996. Foi assessora do Conselho da Comunidade Solidária (1997-2002).

Contato: elisabete.ferrarezi@ enap.gov.br 